\title{
Do You Take Care of Those Who Care?
}

\section{Jones GM* and Ceberio MR}

Neuroscience and Social Sciences Research Laboratory (LINCS), University of Flores (UFLO), Argentina

*Corresponding author: Gilda Mariel Jones, Neuroscience and Social Sciences Research Laboratory (LINCS), University of Flores (UFLO), Argentina, Email: mariel_psico@yahoo.com.

\section{Editorial}

Volume 5 Issue 2

Received Date: November 02, 2021

Published Date: November 12, 2021

DOI: $10.23880 /$ mhrij-16000154 ar

\section{Editorial}

Without a doubt, 2020 turned out to be an unprecedented year in terms of crises of all kinds. The COVID-19 pandemic challenged each of the systems involved and revealed all kinds of problems that were already being perceived, that is. In this scenario, uncertainty was and is one of the main protagonists generating great anxiety in different groups of the population. Within which it could be said that health professionals are the most punished, being in the "Line of fire", facing risk situations for their physical and mental integrity with high levels of stress, having to deal with the uncertainty of others and their own, Nor has it been able to give an adequate response in many cases, suffering from lack of resources, information, overload, exposure to contagion, fear for one's own family and even discrimination (despite receiving applause from around the world at 8:00 p.m. every day).

This leads to thinking about the different emotional pathologies that may have increased in this population, among which could be counted: secondary traumatic stress or empathy exhaustion, which is the result of the stress generated by wanting to help people in suffering, producing the latter the reduction of the ability and interest to deal with the suffering of others, depression, substance abuse, self-medication, burnout, among others. The list is long. This editorial is going to emphasize burnout, which is one of the most evident pictures at the moment; This is a syndrome that is increasingly seen among professionals around the world, bringing a high cost to employees, organizations and their users [1]. The concept of burnout refers to a type of chronic work stress, specifically given in those professionals who maintain a relationship and direct contact with people, especially in care relationships. Burnout is a syndrome also called "burnout syndrome" [2], it is an inadequate response to coping with emotional stress and chronic work tension.

One of the most affected groups is that of health professionals (doctors, nurses, psychologists, psychiatrists, etc.). This population is fundamentally vulnerable due to the complexity of the circumstances that they must face in their work (high emotional involvement, excess of negative stimuli, contact with patients, frustration of not being able to heal, conflict and role ambiguity [3].

Maslach C, et al. [4] point out three main characteristics for this syndrome:

- Emotional fatigue: feeling of emptiness, exhaustion, indifference towards the patient), which implies that it generates emotionally independent bonds of the patients and reducing the encounters with them to the minimum required, a phenomenon that can become indifference and lack of interest in the needs of the other [5].

- Depersonalization: it involves a behavior of contempt, with a lack of courtesy, cynicism and detachment towards patients.

- Lack of personal fulfillment: the subject suffers a loss of interest in their work, low productivity and an undermining of their self-esteem, a situation that can lead to depression [6].

In 2000, the burnout syndrome was declared by the World Health Organization as an occupational risk factor due to its ability to affect quality of life, mental health and even put life at risk. Before the pandemic, a significant incidence of this condition could be observed, perhaps aggravated by the "omnipotence" that many health professionals suffer from having the weight of the belief that "they cannot get sick" and that it is also promoted by the collective imaginary, leading 


\section{Mental Health \& Human Resilience International Journal}

them to risk situations and perhaps a low awareness of illness and lack of self-care, difficulties in asking for help, isolation, etc. Before the start of the pandemic, there were already several studies that showed that there was a high prevalence of emotional exhaustion in health workers, for example in Latin America, a study carried out with 11,530 health professionals, found a prevalence of burn out syndrome of 14, 9\% in Spain, 14.4\% in Argentina, 7.9\% in Uruguay and between 2.5 and 5.9\% in Mexico, Ecuador, Peru, Colombia, Guatemala and El Salvador. Nursing had a prevalence of 7.2\% [7].

Another study Molina NC, et al. [8] carried out a systematic-exploratory review of Burnout syndrome in physicians during the years 2012-2018 in Latin America, the country with the most studies was Mexico, followed by Brazil and Colombia. The male gender predominated, since in this there is a general prevalence of the syndrome; It was found that there is a high prevalence (45.88\%) in emotional exhaustion and depersonalization and low in personal fulfillment in resident doctors. This phenomenon was observed especially in the male gender. These findings show the vulnerability in which physicians are when suffering from Burnout syndrome. Given the aforementioned situation and observing the data, it is possible to reflect on how all this may have worsened in the middle of the COVID-19 pandemic, since here the great ignorance of the disease and the lack of protocols and equipment of adequate personal protection exacerbating stress in health professionals. Of course, numerous researchers came to the crossroads to study the new situation in order to determine the prevalence of Burnout Syndrome and degree of affectation in health professionals, and thus be able to give guidelines for the prevention or reduction of its development. Results: For example, in a study Ascencio GQ, et al. [9] in its results it was observed that in 168 health professionals, $2 \%$ did not present data of affectation, 57\% presented moderate affectation and $41 \%$ presented affectation serious, showing this a burnout prevalence of $98 \%$. Making a comparative analysis of burnout in health professionals, it was found that in Argentina a condition of $16.8 \%$ had been observed in doctors and $4.9 \%$ in nurses prior to COVID-19. Already during the pandemic, a Colombian study showed that $70 \%$ of general practitioners had anxiety or stress, in Ecuador it could be shown that about 95\% suffered from burnout syndrome.

The interventions most used to alleviate this syndrome have been social support, psycho-education, and training in problem solving and communication skills [10]. Protective factors to prevent can be personal or organizational. Among the personal are: perception of self-efficacy, self-esteem and self-confidence [11], feeling of job competence and management of coping techniques) [12,13]. Regarding the organizational factors, there are: group cohesion and support, the relationship of mutual trust, the holding of periodic interdisciplinary meetings, the evaluation of the degree of satisfaction of the health team, the planning of conditions and the delimitation of the functions. and tasks of each team member $[12,13]$.

There are many studies on burnout, but there is not much about the effectiveness of the interventions.

- Laurenţiu P, et al. [14] has reported two main types of interventions for this syndrome: those that help the individual to cope with stressors in the workplace, and interventions focused on making changes to organizational factors. Within the individual ones are those that are based on cognitive behavioral techniques, meditation, relaxation, etc. And regarding the changes in the organization Laurentiu P, et al. [14] aim at generating a positive work climate and support groups.

- Although these interventions increase self-efficacy, they do not have a significant effect on reducing or preventing burnout. Interventions focused on developing workrelated knowledge and skills are based on the assumption that employees improve stress management by using their new skills.

- The approaches to be carried out must be multicomponent, involving the spiritual, professional, emotional intelligence and leadership aspects. The strategies that have implemented social support and supervision have reported positive results in modulating Burnout.

- Given the current global socio-health crisis, more than ever relevance should be given to the development of prevention and intervention strategies in order to raise awareness among health professionals at risk, so that they can recognize the symptoms of pathologies associated with the disease. Work context and provide them with adequate coping skills. Likewise, a series of organizational measures should be taken to reduce and prevent the effects produced by this syndrome in this population.

- It is important to reflect on the risks in psychophysical health and therefore also in the quality of life of these professionals since there are numerous negative consequences that burn out brings.

- The World Health Organization warns that the care of health human resources is essential for the proper implementation of the health policies of the states.

- It is important to think that through proper awareness and prevention situations such as: increased medical leave, and absenteeism, etc., would be avoided $[15,16]$.

- It should not be forgotten that by promoting self-care in health professionals, and intervening effectively in them, the patient, a fundamental actor in this complex system, also benefits.

- Given this, it is really necessary to expand the studies 


\section{Mental Health \& Human Resilience International Journal}

that account for the effectiveness of the different interventions, especially in the current times.

\section{References}

1. Morse GM, Salyers MP, Rollins AL, De Vita M, Pfahler, C (2012) Burnout in mental health services: A review of the problem and its remediation. Adm Policy Ment Health 39(5): 341-352.

2. López Mato AM

Psychoneuroimmunoendocrinology. In: $3^{\text {rd }}$ (Edn.), the last will be the first. Buenos Aires, Argentina: Sciens.

3. Ruiz CO, Ríos FL (2004) Burnout or syndrome of being burned in health professionals: review and perspectives. International Journal of Clinical and Health Psychology 4: $137-160$.

4. Maslach C, Jackson SE (1985) The role of sex and family variables in burnout. Sex Roles 12: 837-851.

5. Italia S, Favara C, Di Cataldo A, Russo G (2008) Evaluation and art therapy treatment of the burnout syndrome in oncology units. Psychooncology 17(7): 676-680.

6. Tuesca R, Iguarán M, Suárez M, Vargas G, Vergara D (2006) Burnout syndrome in nurses in the metropolitan area of Barranquilla. Uninorte Health 22(2): 84-91.

7. Grau A, Flichtentrei D, Suñer R, Prats M, Braga F (2009) Influence of personal, professional and transnational factors in the burnout syndrome in Hispanic American and Spanish health personnel. Rev Esp Public Health 83(2): 215-230.

8. Molina NC, Mena JA, Osorio LP, Salazar LG, Fernández MA (2019) Prevalence of Burnout syndrome in IberoAmerican physicians between 2012 and 2018: a systematic review. Knowledge Dialogues 50: 39-60.
9. Ascencio GQ, Vergara Orozco MG, Yáñez Campos M, Guerrero PP, Ponce RM, et al. (2021) Prevalence of Burnout syndrome in health professionals in the face of a COVID-19 pandemic. Jalisco Health 8: 20-32.

10. Vargas Cruz LD, Niño Cardozo CL, Acosta Maldonado YY (2017) Strategies that modulate the Burnout syndrome in nurses: a bibliographic review. Rev cienc city 14(1): 111-131.

11. Edwards D, Burnard P (2003) A systematic review of stress and stress management interventions for mental health nurses. J Adv Nurs 42 (2): 169-200.

12. Ourcilleón A, Abarca C, Puentes MV, Rodríguez P (2007) Burnout in intensive care nursing professionals. Rev Chil Med Inten 22(2): 83-92.

13. Vázquez J, Vázquez J, Álvarez M, Reyes M, Martínez R, et al. (2012) Intensive group psychotherapeutic intervention carried out in a natural environment for the treatment of burnout in an oncology nursing team. Psychooncology 9(1): 161-182.

14. Laurenţiu P, Sava FA, Butta O (2016) The effectiveness of controlled interventions on employees' burnout: A metaanalysis. Journal of Occupational and Organizational Psychology 89 (1): 1-27.

15. Betta R, Morales G, Rodriguez K, Guerra C (2007) The frequency of emission of self-care behaviors and its relationship with the levels of secondary traumatic stress and depression in clinical psychologists. Psychological Thinking 3: 9-19.

16. Maslach C, Jackson SE, Leiter MP (1986) Maslach Burnout Inventory Manual. In: $2^{\text {nd }}(E d n)$, Palo Alto, CA: Consulting Psychologists Press. 